\title{
OBITUARY
}

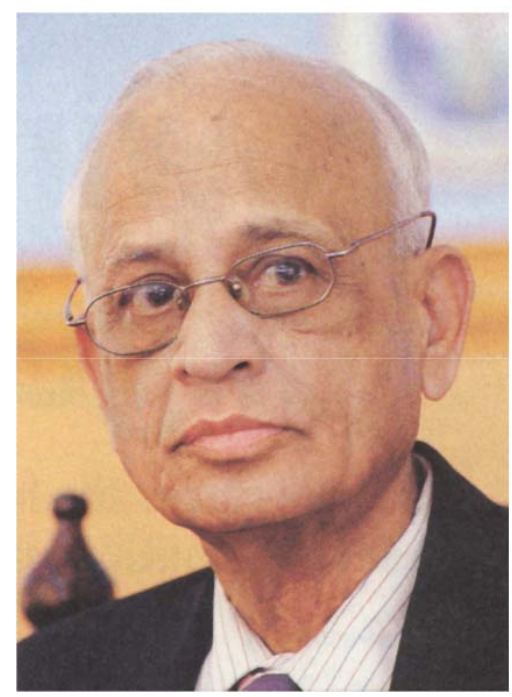

Padmanabhan (P) Krishnagopalan (K) Iyengar

(1931-2011)

It is with deep regret I have to record the death of Padmanabhan Krishnagopalan (PK) Iyengar, , the noted nuclear physicist, on 21 December 2011. He was born in Tirunelveli, Tamil Nadu and had his early education in Thiruvananthapuram. He migrated to Bombay (Mumbai) to join the Tata Institute of Fundamental Research, and soon became an ardent pupil of Homi Bhabha, Vikram Sarabhai, Raja Ramanna and such other stalwarts. He was sent to the Chalk River Laboratories of the Canadian Atomic Energy Establishment to work under Dr. B.N. Brockhouse, a Nobel Laureate in Physics. Those were the early days of the dawn of nuclear power. The sharp intellect of Dr. Iyengar took no time in grasping the intricacies of the new technology that was taking shape. He lead a team that indigenously designed and developed Dhruva and Purnima reactors. What is more, he soon became a member of an inner group of specialists with the leadership of Raja Ramanna at Pokharan in Rajasthan - where India's first Peaceful Nuclear Explosion (PNE), euphemistically called 'Operation Smiling Buddha', was exploded in May 1974.

Nuclear power is the cheapest and safest form for providing electrical energy. It demands very little nuclear fuel and heavy water and yet, there is, in general a growing apathy towards the production of nuclear power. Dr. Iyengar, however, had been a champion for the cause of nuclear power generation from the very beginning. He was, in fact, highly critical of the ways the government of India was negotiating with foreign governments for aid, needlessly and adversely affecting indigenous progress. In the sudden death of Dr. Iyengar, we have lost one of the great champions for the successful production of nuclear power, for, he had firmly believed that it was the only way to bring out real industrial revolution in India.

We mourn the loss of a leader of a rare ability, full of confidence in himself and in his convictions to lead his country on the path of progress.

15 January 2012

B.P. RADHAKRISHNA

\section{Prof. Augusto Gansser}

We regret to inform the passing away of Prof. Augusto Gansser, renowned Himalayan Geologist and the First Honorary Fellow of the Geological Society of India, on 9 January 2012 at Massagno, Switzerland at the age of 101. A detailed note on Prof. Gansser will appear in the forthcoming issue of the Journal. 